\title{
Comunicação
}

[Communication]

\section{Efeito da lactulose sobre os teores séricos de ureia, creatinina, cálcio e fósforo em cães não azotêmicos}

[Effect of lactulose on serum urea, creatinine, calcium and phosphorus in non-azothemic dogs]

\author{
J.A. Pereira ${ }^{1}$, R.C.C.M. Botteon ${ }^{2}$, J.P.N. Barros ${ }^{1}$, K.K.F. Santos ${ }^{3}$, \\ P. Oliveira ${ }^{4}$, M.B. Almeida ${ }^{4}$
}

\footnotetext{
${ }^{1}$ Aluno de pós-graduação - Universidade Federal Rural do Rio de Janeiro - IV-UFRRJ - Seropédica, RJ

${ }^{2}$ Universidade Federal Rural do Rio de Janeiro - Instituto de Veterinária - IV-UFRRJ - Seropédica, RJ

${ }^{3}$ Programa de Pós-Graduação - Universidade de Franca - Unifran - Franca, SP

${ }^{4}$ Aluna de graduação - Universidade Federal Rural do Rio de Janeiro - IV-UFRRJ - Seropédica, RJ
}

A doença renal crônica (DRC), definida como falência renal que persiste por meses ou anos, é uma importante causa de morbidade e mortalidade em cães de diferentes idades (Brown et al., 1997). Independentemente da causa primária, os pacientes portadores de DRC apresentam lesões estruturais renais progressivas e irreversíveis, caracterizadas por uma crescente incapacidade do rim em manter níveis normais dos produtos do metabolismo das proteínas e valores normais da pressão arterial e do hematócrito; do equilíbrio hídrico, eletrolítico e ácido-básico. O tratamento geralmente é sintomático, com o objetivo de minimizar os danos renais e manter baixos os componentes nitrogenados não proteicos no sangue, e deve concentrar-se na correção dos desequilíbrios de líquidos, eletrólitos, vitaminas e minerais (Kovesdy, 2010).

Prebióticos são ingredientes não digestíveis, capazes de influenciar seletivamente o crescimento e/ou a atividade de bactérias do trato digestivo e promover o crescimento e a atividade de bactérias benéficas (Bergen e Wu, 2009). A lactulose, um dissacarídeo formado pela reação entre frutose e galactose, aumenta a capacidade fermentativa de bifidobactérias e Lactobacillus, e estas diminuem competitivamente a microbiota produtora de urease (Schumann, 2002), ao mesmo tempo em que promove aumento da assimilação de ureia por bactérias. Dessa forma, é utilizada em pacientes humanos com

Recebido em 31 de março de 2013

Aceito em 1 de outubro de 2013

E-mail: julianabreu_vet@hotmail.com insuficiência hepática visando ao controle da produção de ureia e amônia (De Preter et al., 2006). Em animais, foi relatada sua utilização em um cão com anomalia vascular portossistêmica congênita (Brum et al., 2007).

Mediante a possibilidade de controle da uremia, avaliaram-se os níveis séricos de ureia, creatinina, cálcio e fósforo em cães com parâmetros bioquímicos séricos indicativos de função renal normal (não azotêmicos) por meio da utilização continuada de lactulose por via oral.

De acordo com as diretrizes da Universidade Federal Rural do Rio de Janeiro, o projeto foi aprovado pelo Comitê de Ética em Pesquisa (Protocolo n ${ }^{\circ}$ 23083.011.976/2011-00).

Doze cães da raça Beagle, machos, acima de sete anos de idade, foram selecionados de forma a atender aos seguintes critérios: condição clínica geral satisfatória, assintomáticos (doenças parasitárias, infecciosas, metabólicas ou neoplásicas), sem histórico de enfermidades préexistentes e com parâmetros bioquímicos séricos indicativos de função renal normal (ureia $\leq 60,0 \mathrm{mg} / \mathrm{dL}$ e creatinina $\leq 1,50 \mathrm{mg} / \mathrm{dL}$ ). Os animais nessas condições foram inseridos em um ensaio experimental, constituindo dois grupos: G1(n=6) - manejo e alimentação normais; e G2 $(\mathrm{n}=6)$ - lactulose $\left(\right.$ Colonac $^{\circledR}$, União Química Farmacêutica Nacional S/A, Pouso Alegre, Minas Gerais) em duas doses diárias de $1 \mathrm{~mL} / \mathrm{kg}$ (equivalente a $667 \mathrm{mg} / \mathrm{kg}$ ), por via oral, em 
intervalos de 12 horas, por 30 dias, com manejo e alimentação semelhantes ao G1. Os animais de ambos os grupos foram avaliados diariamente.

No início do tratamento (D0), e aos sete (D7), 21 (D21) e 30 dias (D30), amostras de sangue foram colhidas pela manhã, por punção da veia cefálica, acondicionadas em tubos sem anticoagulante. Os frascos foram mantidos inclinados, em temperatura de $4^{\circ} \mathrm{C}$, até a completa coagulação e retração do coágulo. A seguir, foram centrifugadas (15 minutos a $1500 \mathrm{~g}$ ), e do soro foram determinadas por espectrofotometria as concentrações de ureia (Bioclin K047), creatinina (Bioclin K016), cálcio (Bioclin K007) e fósforo (Bioclin K020), segundo especificação do fabricante. As amostras foram analisadas em triplicata, utilizando-se as médias dos valores obtidos.

Os dados foram avaliados quanto à distribuição paramétrica, sendo usado o método de Levine. Aqueles que apresentaram distribuição normal foram comparados por análise de variância (parcelas subdivididas no tempo), e as variáveis não paramétricas foram analisadas pelo teste de Kruskal-Wallis. Em todos os testes, foi utilizado o grau de confiança de $95 \%$.

Todos os animais (G1 e G2) mantiveram comportamento normal, bem como não apresentaram alterações relevantes de estado geral (peso), apetite e ingestão hídrica. As mucosas apresentaram-se brilhantes e úmidas, e o tempo de preenchimento capilar (TPC) manteve-se dentro dos padrões de normalidade (1-2 segundos).
As fezes apresentaram cor e odor normais, sem a presença de elementos anormais, com consistência firme e modelada nos animais sem lactulose (G1), porém mais fluidas durante o tratamento com lactulose (G2). As alterações na consistência das fezes são justificadas pela presença de glicose e ácido lático nas fezes e decorrente estímulo à passagem de água do meio extracelular para o lúmen intestinal, o que confere um efeito laxativo por aumento da osmolaridade do conteúdo intestinal à lactulose.

Em conjunto, os achados clínicos indicam ausência de efeito da lactulose sobre a condição orgânica geral de animais com função renal normal, sendo o amolecimento das fezes consequência do efeito osmótico da lactulose, semelhante à descrição de Kamphes et al. (2003) em suínos, não relevante no que se refere à hidratação visto que todos os animais mantiveram as mucosas úmidas e brilhantes e o TPC de 1-2 segundos.

Apesar da tendência de redução dos valores séricos de ureia nos animais tratados com lactulose (G2), a diferença não foi significativa em relação aos animais não tratados. Também não foram significativas as variações nos níveis de creatinina (Tab. 1). Valores normais de creatinina em todos os momentos indicam adequada filtração glomerular, coerente com a condição de normalidade da função renal estabelecida para os animais e sem interferência relevante da lactulose. A lactulose, portanto, não alterou de forma significativa os níveis séricos de ureia e creatinina em cães não azotêmicos.

Tabela 1. Valores séricos (média e desvio-padrão) de ureia, creatinina, cálcio e fósforo em cães não azotêmicos, com manejo e alimentação normais, sem lactulose (G1) e tratados com lactulose (G2) $\left(\right.$ Colonac $\left.^{\circledR}\right)$ em duas doses diárias $(1 \mathrm{~mL} / \mathrm{kg})$, por via oral, em intervalos de 12 horas, por 30 dias

\begin{tabular}{lcccccccc}
\hline Tratamentos $\rightarrow$ & \multicolumn{3}{c}{ G1 (SEM lactulose) } & \multicolumn{3}{c}{ G2 (COM lactulose) } \\
\hline Dias $\rightarrow$ & D 0 & D 7 & D 21 & D 30 & D 0 & D 7 & D 21 & D 30 \\
\hline Ureia & $30,7 \mathrm{Aa}$ & $35,5 \mathrm{Aa}$ & $33,5 \mathrm{Aa}$ & $39,0 \mathrm{Aa}$ & $32,3 \mathrm{Aa}$ & $39,5 \mathrm{Aa}$ & $31,7 \mathrm{Aa}$ & $32,8 \mathrm{Aa}$ \\
\hline Creatinina & $0,7 \mathrm{Aa}$ & $0,7 \mathrm{Aa}$ & $0,7 \mathrm{Aa}$ & $0,8 \mathrm{Aa}$ & $0,8 \mathrm{Aa}$ & $0,8 \mathrm{Aa}$ & $0,8 \mathrm{Aa}$ & $0,7 \mathrm{Aa}$ \\
Cálcio & $7,3 \mathrm{Aa}$ & $9,9 \mathrm{Ba}$ & $9,3 \mathrm{Ba}$ & $9,2 \mathrm{Ba}$ & $7,9 \mathrm{ABa}$ & $7,1 \mathrm{ABa}$ & $7,9 \mathrm{ABa}$ & $6,6 \mathrm{ABb}$ \\
Fósforo & $4,07 \mathrm{Aa}$ & $4,2 \mathrm{Aa}$ & $4,7 \mathrm{Aa}$ & $4,6 \mathrm{Aa}$ & $3,95 \mathrm{Aa}$ & $3,3 \mathrm{Aa}$ & $2,85 \mathrm{Bab}$ & $2,7 \mathrm{Bab}$ \\
\hline
\end{tabular}

Referências: ureia 10-60 UI/L (Kaneko et al., 2008); creatinina 0,5-1,4mg/dL (Willard e Tvedten, 2012); cálcio 9,011,9mg/dL (Willard e Tvedten, 2012); fósforo 1,9-7,9mg/dL (Willard e Tvedten, 2012).

Números seguidos de letras diferentes na mesma linha indicam diferença significativa a $95 \%$ entre momentos de avaliação (maiúsculas) e tratamentos (minúsculas). 
A abordagem do metabolismo ósseo e mineral em pacientes com DRC sustenta-se na necessidade de garantir o equilíbrio de $\mathrm{Ca}$ e $\mathrm{P}$ para manter adequados os níveis de paratormônio (PTH) e a remodelação normal dos ossos. A concentração plasmática de fosfato, que geralmente permanece normal nos estágios iniciais da DRC, aumenta progressivamente à medida que a taxa de filtração glomerular cai, surgindo hiperfosfatemia e suas consequências (Malluche e Mawad, 2002).

Nos cães não tratados com lactulose (G1), os valores obtidos para o cálcio nos dias sete, $21 \mathrm{e}$ 30 foram maiores, com diferença significativa em relação ao D0. No grupo com lactulose $(\mathrm{G} 2)$, as médias foram menores no dia 30, abaixo de $9,0 \mathrm{mg} / \mathrm{dL}$ em todos os momentos, mas sem diferença significativa (Tab. 1). Os valores de D7 do grupo controle foram significativamente maiores que no D30 do grupo lactulose $(\mathrm{p}=0,0058)$.

No início (D0), a maioria dos cães (G1 e G2) apresentaram calcemia abaixo de $9,0 \mathrm{mg} / \mathrm{dL}$ (Willard e Tvedten, 2012), com valores normais ou ligeiramente baixos nos dias sete, 21 e 30 . Nenhum dos animais apresentou sinais clínicos de hipocalcemia.

Rocha et al. (2009), ao analisarem os níveis séricos de $\mathrm{Ca}$ e $\mathrm{P}$ em animais portadores e não portadores de DRC, identificaram que as dosagens de cálcio total não variaram significativamente entre os grupos, sendo encontradas, igualmente ao presente estudo, médias abaixo dos limites descritos como fisiológicos para os animais do grupo controle $(6,51 \pm 2,86 \mathrm{mg} / \mathrm{dL})$ e para o grupo doente $(6,38 \pm 1,71 \mathrm{mg} / \mathrm{dL})$.

Enfermidades renais, hepáticas, pancreáticas e metabólicas não estão provavelmente relacionadas aos valores subnormais do cálcio neste estudo, pelas condições de normalidade dos animais (assintomáticos). A variabilidade obtida na concentração sérica do cálcio total pode resultar de diferenças na idade, na dieta, no período de jejum que antecedeu a colheita e no processamento da amostra. Pequenas variações podem ser justificadas pela temperatura dearmazenamento do sangue após a colheita e pelo tempo de separação do soro ou plasma. Outros fatores interferentes são: hemólise, lipemia, bilirrubina, citrato, oxalato, exercício, hipertensão e concentração de proteínas, especialmente albumina (Kaneko et al., 2008).

Um fator a ser considerado é a idade dos animais (acima de oito anos), visto que o teor de cálcio sérico tende a diminuir com a idade (Dias, 2012) devido à menor eficiência de absorção, menor eficiência de síntese de colecalciferol, menor exposição solar, diminuição na hidroxilação hepática e renal da vitamina $\mathrm{D}$ e tendência de balanços negativos de cálcio nos ossos (Schenk e Chew, 2008).

Se houver hipoproteinemia, fenômeno comum no paciente idoso, as determinações do cálcio total podem demonstrar falsa hipocalcemia e a medição de cálcio total deve ajustar-se a proteínas (Navarro-Moreno e Alía-Ramos, 2006).

A fosfatemia em ambos os grupos variou dentro dos limites de referência para a espécie, sem diferença estatisticamente significante no grupo controle (Tab.1). Nos animais tratados com lactulose, a fosfatemia teve redução progressiva, com diferença significativa $(p=0,0024)$ nos dias 21 e 30 comparativamente ao D0 e ao D7, com diferenças significativas em relação aos controles em todos os momentos.

Como não foram localizados relatos sobre a fosfatemia tanto na literatura médica quanto na veterinária, os resultados foram satisfatórios, visto que, além da possibilidade de atuar no controle da uremia, a lactulose pode ser útil também no controle da hiperfosfatemia, um dos principais problemas metabólicos secundários na nefropatia crônica. Para esse efeito, sugere-se que, ao atuar no metabolismo dos compostos nitrogenados com redução dos valores séricos de ureia, a lactulose atue sobre o equilíbrio ácidobásico, no controle da acidose metabólica e, indiretamente, na homeostase dos minerais cálcio e fósforo. 
Pelo conjunto dos achados clínicos, conclui-se ausência de efeito da lactulose sobre a condição clínica e orgânica geral de animais não azotêmicos. A lactulose na dose administrada alterou a consistência das fezes, porém sem efeito sobre a hidratação e a condição clínica dos animais. A lactulose não alterou de forma relevante os níveis de ureia e creatinina em cães não azotêmicos. Os efeitos mais significativos do tratamento com lactulose foram relacionados ao metabolismo Ca:P, havendo uma redução progressiva dos níveis séricos de fósforo.

Palavras-chave: lactulose, prebióticos, fosfatemia, calcemia, uremia

\begin{abstract}
The present study evaluated serum levels of urea, creatinine, calcium and phosphorus in non-azothemic dogs by continued use of lactulose orally. Serum levels of urea, creatinine, calcium and phosphorus were determined in Beagle dogs, clinically healthy and without biochemical changes (non-azothemic), undergoing oral treatment with lactulose $(n=6)$, for a period of 30 days. The prebiotic showed no significant lowering effect on serum urea and creatinine, but the values of calcium and phosphorus, as well as their relation, were modified with reduced serum phosphorus levels in animals treated with lactulose compared to controls, with a significant difference.
\end{abstract}

Keywords: lactulose, prebiotics, phosphatemia, calcemia, uraemia

\section{REFERÊNCIAS}

BERGEN, W.G.; WU, G. Intestinal nitrogen recycling and utilization in health and disease. $J$. Nutr., v.12, p.1-5, 2009. Disponível em: http://jn.nutrition.org/content/early/2009/03/12/jn .109.104497.full.pdf+html

BROWN, S.A; CROWELL, W.A.; BROWN C.A.; BARSANTI J.A. et al. Pathophysiology and management of progressive renal disease. Vet. J., v.154, p.93-109, 1997.

BRUM, A.M.; CHAMPION, T.; ZANATTA, R.; COSTA, M.T. et al. Utilização de probiótico e de lactulose no controle de hiperamonemia causada por desvio vascular portossistêmico congênito em um cão. Cienc. Rural, v.37, p.572-574, 2007.

DE PRETER, V., VANHOUTTE, T.; HUYS, G.; SWINGS, J. et al. Effect of lactulose and Saccharomyces boulardii administration on the colonic urea-nitrogen metabolism and the bifidobacteria concentration in healthy human subjects. Alim. Pharm. Therap., v.23, p.963-974, 2006.

DIAS, D.D.J. Estudo dos níveis séricos de cálcio ionizado em doença periodontal em canídeos em função do sexo, idade e peso vivo. 2012. 79p. Dissertação (Mestrado Integrado em Medicina Veterinária). Universidade Técnica de Lisboa. Disponível em: https://www.repository.utl.pt/ handle/10400.5/4330. Acessado em: 17 jul. 2013.
KAMPHES, J.; TABELING, R.; STUKE, O. Possible interesting dietetic effects of lactulose as a feed additive in pig feed. Dtsch. Tierärztl. Wochenschr, v.110, p.365-368, 2003.

KANEKO, J.J.; HARVEY, J.; BRUSS, M. Clinical Biochemistry of Domestic Animals. 6.ed. San Diego: Academic Press, 2008. 928p.

KOVESDY, C.P. Rate of kidney function decline associates with increased risk of death. J. Am. Soc. Nephr., v.21, p.1814-1816, 2010.

MALLUCHE, H.H.; MAWAD, H. Management of hyperphosphataemia of chronic kidney disease: Lessons from the past and future directions. Nephrol. Dial. Transpl., v.17, p.11701175, 2002.

NAVARRO-MORENO, M. A.; ALÍA-RAMOS, P. Metabolismo ósseo. Vitamina DY PTH. Endocrinol. y Nutr., v.53, p.199-208, 2006.

ROCHA, J.R.; SANTOS, L.M.; BOCARDO, M.; RIBEIRO, T.B. et al. Determinação das concentrações séricas de cálcio e fósforo de cães normais e com insuficiência renal crônica. Rev. Cient. Eletr. Med. Vet., v.7, 2009. Disponível em: http://www.revista.inf.br/veterinaria13/artigos/art $\%$ 2003.pdf 
SCHENCK, P.A.; CHEW, D.J. Calcium: total or ionized? Vet. Clin. North Am. Small Anim. Pract., v.38, p.497-502, 2008.

SCHUMANN, C. Medical, nutritional and technological properties of lactulose. Eur. J. Nutr., v.41, p.17-25, 2002.
WILLARD, M.D.; TVEDTEN, H. Small Animal Clinical Diagnosis by Laboratory Methods. 5. ed. Missouri: Elsevier Saunders, 2012. 427p. 